\title{
VIDEO KABUPATEN TANGERANG PADA DINAS DISPORABUDPAR PARIWISATA
}

\author{
Azwar Aditya Putra ${ }^{1}$ \\ Vella Carisa $^{2}$ \\ Dosen STMIK Raharja ${ }^{1}$, AMIK Raharja Informatika Jurusan Sistem Informasi ${ }^{2}$ \\ Jl. Jendral Sudirman No. 40, Modern Cikokol, Tangerang \\ Email : azwar.aditya.p@raharja.info ${ }^{1)}$, vella@raharja.info ${ }^{2)}$
}

\begin{abstract}
ABSTRAK
Video informasi yang dirancang ini menjelaskan keberagaman dan kekayaan objek wisata yang ada di Kabupaten Tangerang saat ini, sehingga dapat menjadi daya tarik bagi wisatawan lokal maupun asing serta masyarakat, untuk mengetahui informasi wisata yang ada di kabupaten Tangerang. Tujuan penelitian ini adalah Untuk mencapai target Disporabudpar dalam hal menyampaikan informasi tentang objek wisata Kabupaten Tangerang kepada masyarakat dan wisatawan, serta meningkatkan jumlah kunjungan wisatawan setiap tahunnya. Adapun metode penelitian yang digunakan dalam penelitian ini diantaranya Pengumpulan Data, Analisa Perancangan Media, dan Konsep Produksi Media (KPM) yang meliputi : pre production, production,dan post production. Melalui media informasi objek wisata Kabupaten Tangerang yang dirancang akan di informasikan melalui : Youtube, Website Kabupaten Tangerang, Website Disporabudpar dan facebook. Target yang diharapkan Disporabudpar yaitu, wisatawan dan masyarakat dapat mengetahui keanekaragaman objek wisata yang ada di Kabupaten Tangerang, serta dapat meningkatkan jumlah wisatawan yang berkunjung ke Kabupaten Tangerang setiap tahunnya.
\end{abstract}

Kata Kunci : Video, Informasi, Kabupaten Tangerang

\begin{abstract}
Video information designed this explains the diversity and wealth of attractions that exist in the current, so it can be an attraction for both local and foreign tourists as well as the public, to know there is tourist information in Tangerang Regency. The purpose of this research is to achieve the target of Disporabudpar in terms of conveying information about the sights of the Tangerang Regency to the community and tourists, as well as increase the number of tourists visit every year. As for the research methods used in this study include Data collection, analysis of the design of the Media, and the concept of Media Production (KPM) which include: pre production, production, and post production. Tourist information through the medium of Tangerang Regency designed will be informed via the Youtube Website: Tangerang Regency, Disporabudpar Website and facebook. The expected target of Disporabudpar i.e., tourists and the public can know the diversity existing tourist attractions in Tangerang Regency, and can increase the number of tourists visiting the Tangerang Regency each year.

Keywords: Video, Information, Tangerang Regency
\end{abstract}

\section{PENDAHULUAN}

Kabupaten Tangerang memiliki potensi pariwisata yang cukup menarik dan prospektif. Manakala potensi tersebut dapat dikelola dengan baik, termasuk dengan pola promosi yang gigih dan canggih serta mendunia, maka mata rantai obyek-obyek pariwisata di Kabupaten Tangerang akan menjadi salah satu andalan sumber pendapatan daerah sekaligus promosi daerah yang strategis. Kawasan yang memiliki sejarah panjang ini 
menyimpan beragam potensi pariwisata yang menarik untuk menjadi tujuan destinasi wisata. Pembahasan mengenai pariwisata Kabupaten Tangerang ternyata tidak kalah menarik akan keberagamannya. Rata-rata dari mayoritas masyarakatnya sendiri memiliki beragam suku, ras, dan agama yang berbeda mulai dari suku Betawi, Sunda, Jawa, sampai Tionghoa, maupun juga dengan keberagaman agamanya. Masyarakat Kabupaten Tangerang memiliki keberagaman agama yang cukup kaya yaitu didominasi pemeluk agama Islam disusul dengan pemeluk agama Kristen, Katolik, Budha dan yang terakhir Hindu.

\section{RUMUSAN MASALAH}

Merancang media informasi dan promosi yang menarik dan dapat dikenal oleh masyarakat menggunakan video informasi yang dapat menarik perhatian wisatawan untuk berkunjung dan mengenal beragam potensi seni dan bangunan bersejarah di Kabupaten Tangerang ialah video yang menyatukan antara gambar, audio, musik dan berbagai effect visual yang menarik dan dinamis. Agar lebih efektif dan tepat sasaran video ini di implementasikan melalui DVD dan berbagai media sosial seperti youtube, website, dan beberapa acara seni dan kebudayaan.

\section{LANDASAN TEORI}

\section{Pengertian Media}

Alat, sarana, perantara dan penghubung untuk menyebar, membawa atau menyampaikan suatu pesan dan gagasan kepada penerima.

\section{Pengertian Informasi}

Hasil dari pengolahan data menjadi bentuk yang lebih berguna bagi yang menerimanya yang menggambarkan suatu kejadian - kejadian nyata dan dapat digunakan sebagai alat bantu untuk pengambilan suatu keputusan.

\section{Pengertian SWOT}

suatu cara mengidentifikasi berbagai faktor secara sistematis dalam rangka merumusukan strategi perusahaan. Analisis SWOT mempertimbangkan faktor lingkungan internal strengths dan weaknesses serta lingkungan eksternal oportunities dan threats yang dihadapi dunia bisnis. Analisis SWOT didahului dengan indentifikasi posisi perusahaan melalui evaluasi nilai faktor eksternal.

\section{Pengertian Video}

"the storage of audio visuals and their display on television-type screen" yang diartikan penyimpanan atau perekaman gambar dan suara yang penayangannya pada layar televisi."

\section{Pengertian Pariwisata}

Aktivitas dari yang dilakukan oleh wisatawan ke suatu tempat tujuan wisata di luar keseharian dan lingkungan tempat tinggal dengan alasan bukan untuk menetap atau mencari nafkah melainkan hanya untuk bersenang - senang. 


\section{Pengertian Kebudayaan}

Sesuatu yang dihasilkan oleh cipta, rasa, dan karsa manusia yang direfleksikan dalam seni, sastra, religi, dan moral.

\section{Perencanaan Seni}

Hasrat manusia akan keindahan dapat diekspresikan melalui media suara, gerak, karya lukis, dan media seni lainnya.

\section{Tujuan Multimedia}

kombinasi dari beragam bentuk konten seperti teks, audio, video, gambar dan animasi untuk memberikan informasi atau hiburan kepada pengguna.

\section{Tahapan Produksi Audio Visual}

\section{Pra Produksi}

menetapkan sebuah skenario yang disepakati bersama sebagai draf skenario akhir; pembedahan skenario (scenario breakdown); pembuatan papan produksi (production strip board); pembuatan jadwal; membuat perkiraan anggaran; memanggil kru (recruitment); pencarian lokasi; perijinan; pencarian pemain (casting); tanda tangan kontrak kerja; latihan; dan pembuatan call sheet (jadwal shooting).

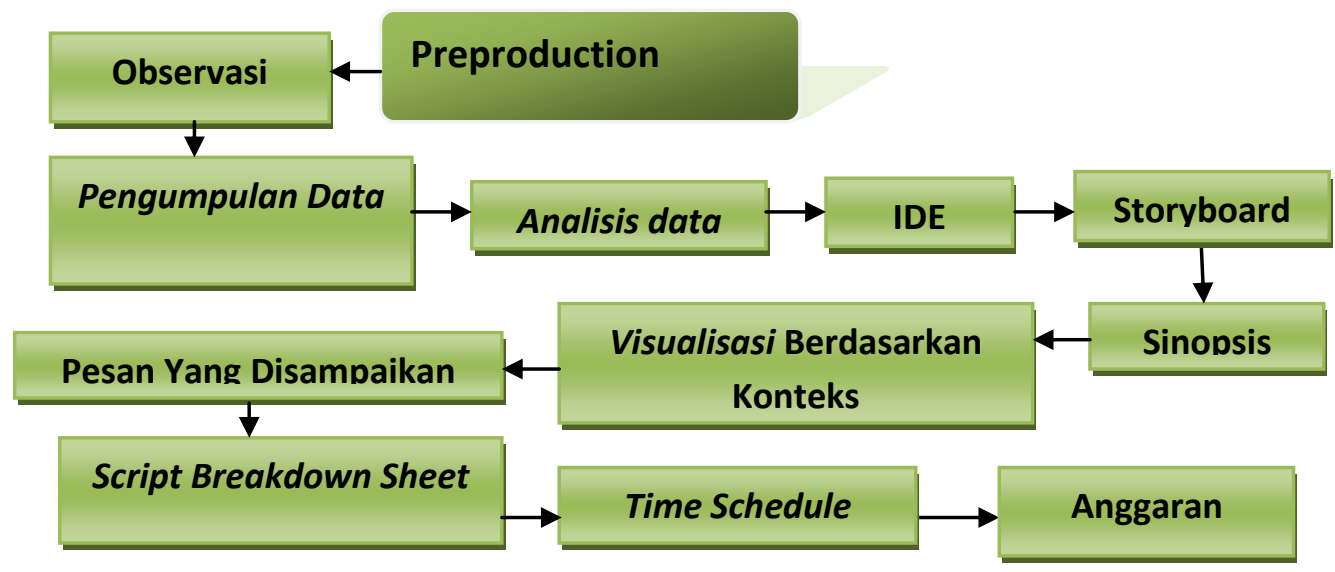

Gambar 1. Tahapan Pra Produksi

\section{Produksi}

"memproduksi program doku-drama agak mirip dengan memproduksi program dokumenter. Namun dalam doku-drama adegan yang terjadi di masa lalu bisa direkayasa." 


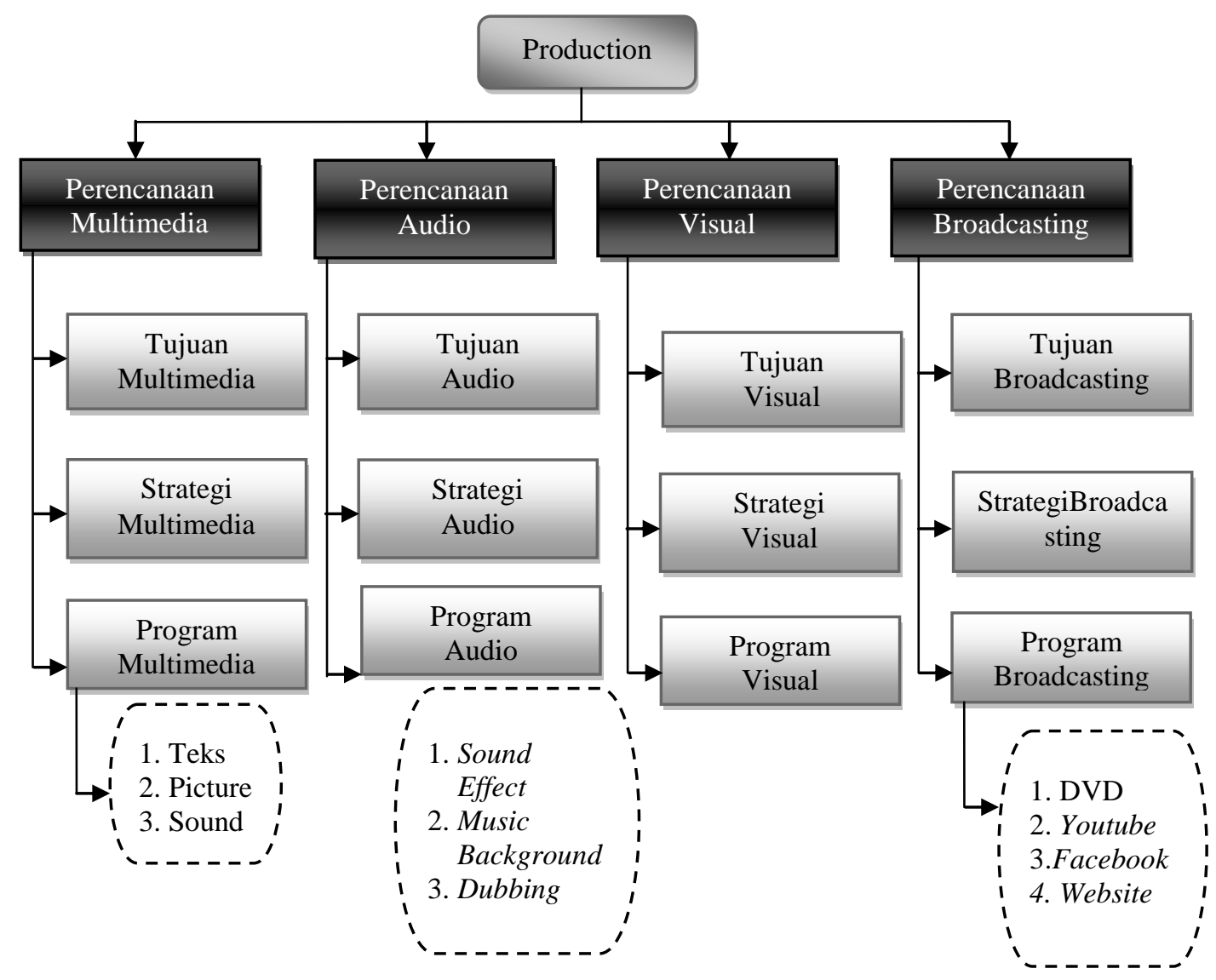

\section{Post Produksi}

Gambar 2. Tahapan Produksi

"Pascaproduksi (penyuntingan) peliputan/shooting/taping sehingga materi selesai disiarkan atau diputar kembali.

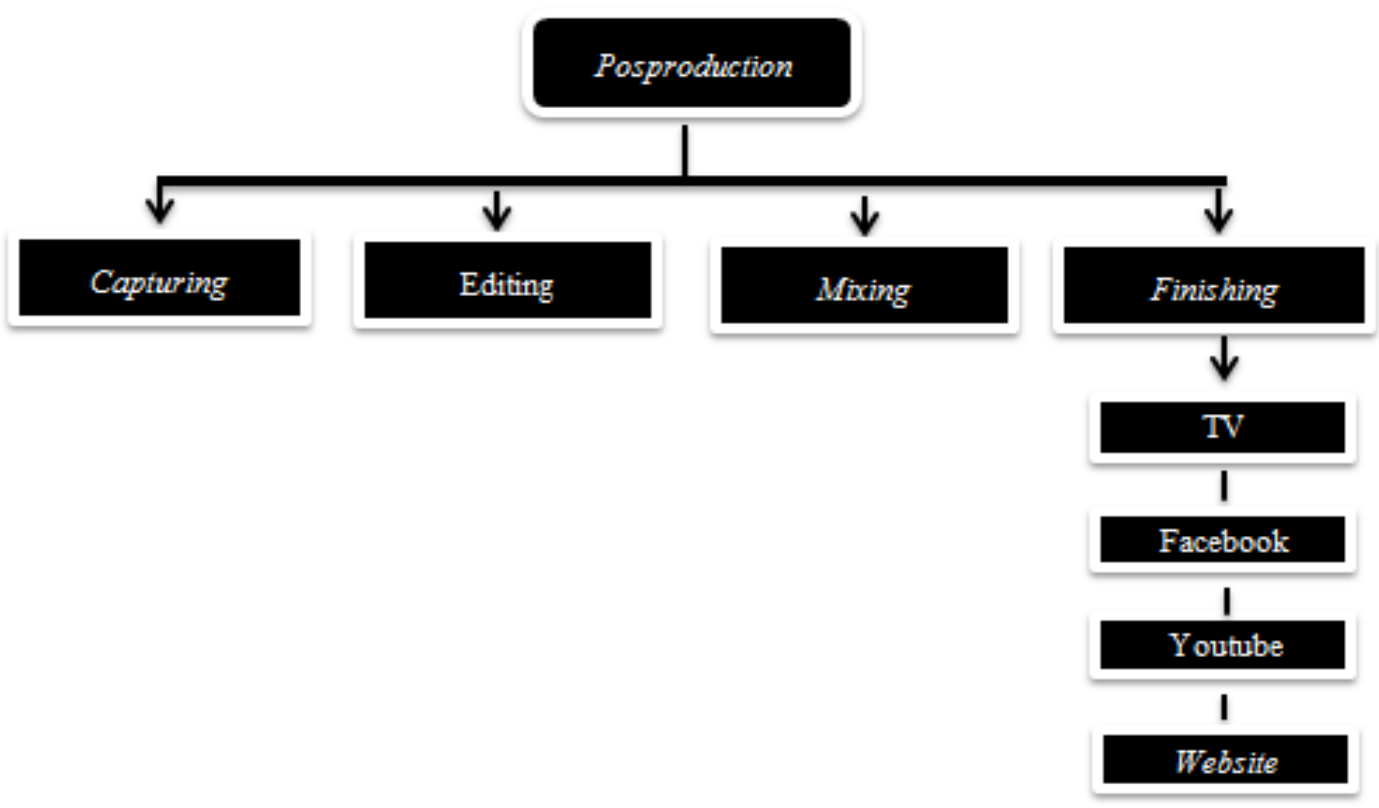

Gambar 3. Pasca Produksi 


\section{Storyboard}

\section{Scene 1}

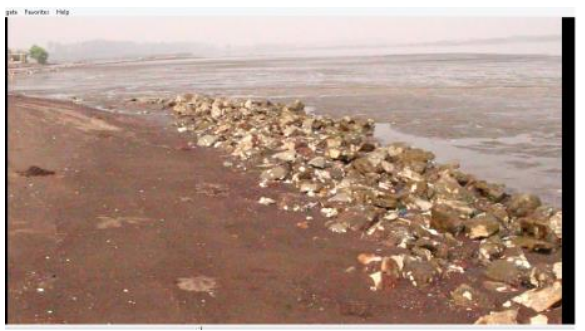

video detinasi wisata bahari

tanjung kait (Full Shoot)

Gambar 4. EXT/video detinasi wisata bahari tanjung kait

\section{Scene 2}

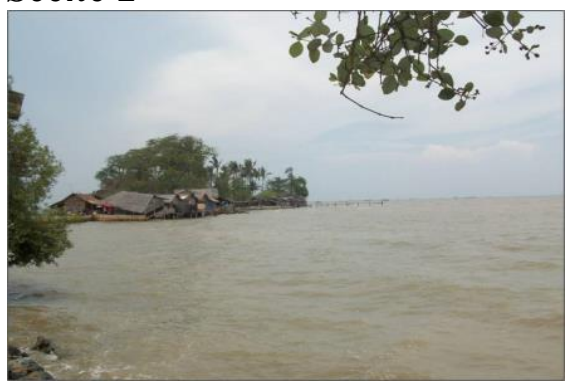

video destinasi wisata pulau cangkir (Long Shoot)

Gambar 5. EXT/video destinasi wisata pulau cangkir

\section{Scene 3}

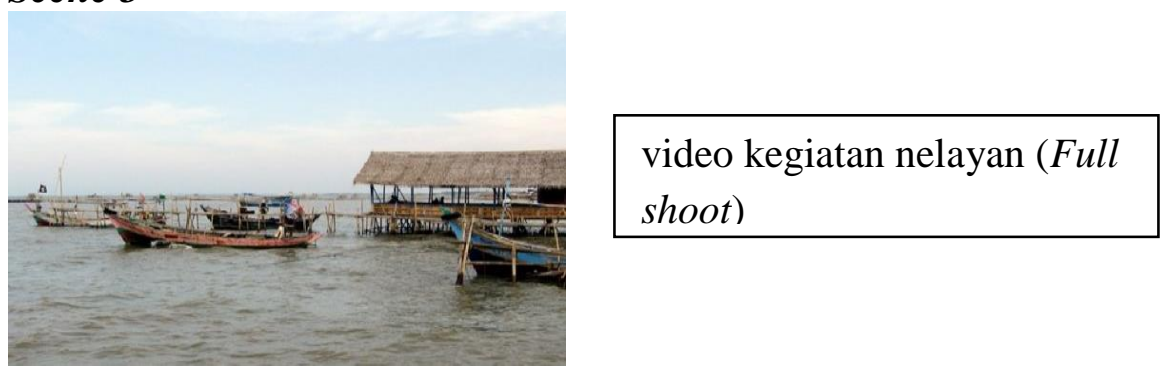

Gambar 6. EXT/video kegiatan nelayan

\section{Scene 4}

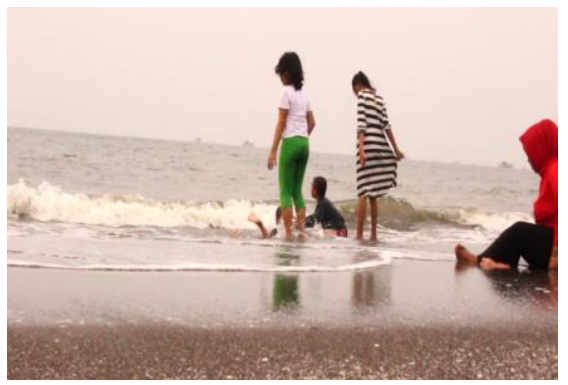

Gambar 7: EXT/ video destinasi wisata tanjung pasir 


\section{Scane 5}

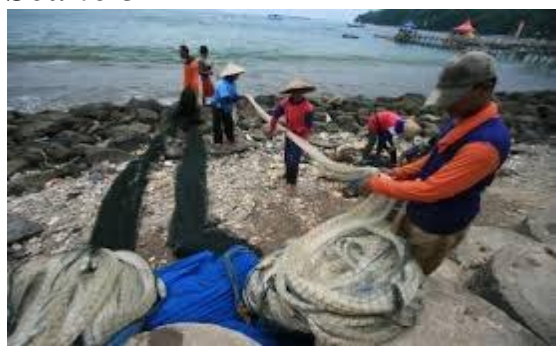

video kegiatan nelayan (Full

Shoot)

Gambar 8. EXT/ video kegiatan nelayan

\section{Scane 6}

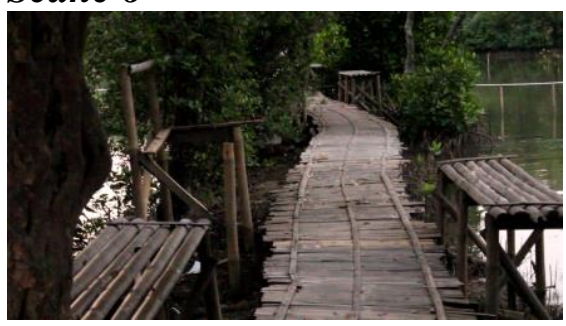

video destinasi wisata hutan mangrove (Full Shoot)

Gambar 9. EXT/ video destinasi wisata hutan mangrove

\section{Scane 7}

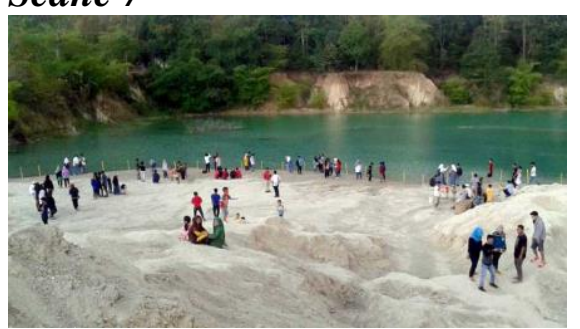

video suasana sekitar danau

biru cisoka

Gambar 10. EXT/ video suasana sekitar danau biru cisoka (Full Shoot)

\section{Scane 8}

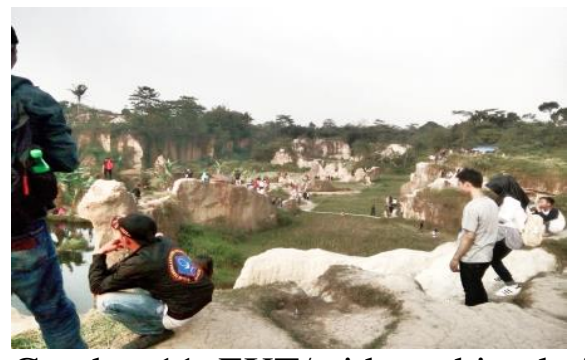

EXT/ video tebing koja

cisoka

Gambar 11. EXT/ video tebing koja cisoka (Medium Shoot)

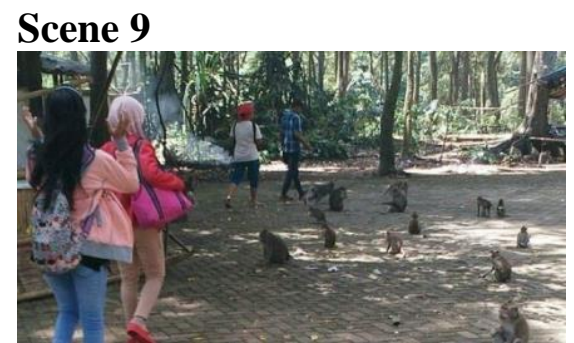

video kegiatan wisatawan dengan kera penunggu

makam

Gambar 12. EXT/ video kegiatan wisatawan dengan kera penunggu makam (Medium Shoot)

\section{Adobe Premier CS6}


digunakan oleh rumah-rumah produksi, televisi dan praktisi di bidangnya Adobe Premiere Pro merupakan program pengolah video pilihan bagi kalangan profesional, terutama yang suka bereksperimen.

\section{Corel After effek CS6}

program pengolah video editing. Adobe After Effect adalah digunakan untuk mengolah dan menambahkan efek - efek khusus dalam pembuat video acara -acara seperti pernikahan, maupun pembuatan iklan di industri.

\section{Adobe Photoshop CS6}

Software (perangkat lunak) buatan Adobe Systems yang digunakan untuk pengeditan foto/gambar, termasuk pembuatan efek grafis. Adobe Photoshop sering digunakan oleh fotografer digital dan perusahaan iklan (advertising).

\section{LITERATUR REVIEW}

1. Penelitian oleh Ramadhan, dkk (2015:3) $)^{[41] ~ " C i t r a ~ P a r i w i s a t a ~ K o t a ~ B a n d u n g ~ S e b a g a i ~}$ Kota Art Deco : Studi Kasus Kawasan Asia Afrika dan Braga”. Bandung memiliki potensi melalui wisata budaya warisan dalam bentuk bangunan tua pariwisata besar berseni Belanda kolonial arsitektur Art Deco yang banyak di Asia Afrika dan Braga. Art Deco mencirikan identitas atau merek Asia Afrika dan Braga. Perbaikan infrastruktur dan revitalisasi budaya dibawa keluar oleh pemerintah kota Bandung baru - baru ini, penelitian ini adalah untuk mengidentifikasi kondisi merek pengetahuan yang terdiri dari kesadaran merek dan citra merek dari Art Deco di kawasan cagar budaya (warisan budaya) Asia-Afrika dan Barga untuk mengukur bagaimana gambar atau identitas pariwisata Bandung sebagai kota Art Deco sebagaimana dinyatakan dalam rencana induk Pariwisata Nasional 2010 - 2025. Penelitian menggunakan metode kuantitatif, contoh yang digunakan adalah 100 wisatawan yang berkunjung ke Asia Afrika dan Braga dengan distribusi kuesioner online. Selain analisis data juga didukung oleh studi sastra dan observasi langsung di situs studi. Hasil analisis menunjukkan bahwa tingkat kesadaran dari wisata Art Deco pada kategori tengah yang berarti wisatawan tidak begitu akrab dengan seni Deco ini adalah karena kurangnya instruksi atau papan informasi tentang Art Deco di sekitar Asia Afrika dan Braga, selain banyak wisatawan sendiri yang tidak tahu ada Art Deco, tapi hasil analisis menunjukkan gambar citra merek dalam kategori baik. Bangunan warisan arsitektur Art Deco terlihat unik dan indah ini memberikan nilai lebih untuk Asia Afrika dan Braga, berdasarkan hal ini dianggap sesuai dengan citra pariwisata di kota Bandung sebagai kota Art Deco.

2. Penelitian oleh Maulani, dkk (2016 : 207 - 220) $)^{[28] ~ " P e n g e m b a n g a n ~ M e d i a ~ P r o m o s i ~}$ Pariwisata Kota Tangerang Dalam Bentuk Video Digital Pada Dinas PORPAREKRAF". Saat ini Dinas PORPAREKRAF, memberikan informasi dan promosi berupa video pariwisata melalui beberapa media yaitu berupa media sosial, maupun website yang dirasa masih belum cukup untuk memenuhi kebutuhan promosi pariwisata yang dirasa kurang uptodate. Dinas PORPAREKRAF harus memiliki 
sarana media informasi dan promosi yang dapat menunjang kemajuan pariwisata Kota Tangerang.

3. Penelitian oleh Hayati (2014: 1) ${ }^{[18]}$ "Pemanfaatan Bangunan Bersejarah Sebagai Wisata Warisan Budaya Di Kota Makassar". Zaman kolonial di Indonesia mewariskan sejumlah bangunan sekolah, bank dan kantor. Bangunan yang memiliki nuansa arsitektur Belanda, oleh karena itu menjadi warisan budaya dan atraksi pariwisata. Tujuan dari penelitian ini adalah untuk mengetahui sejarah pemanfaatan bangunan di kota Makassar, Sulawesi Selatan. Namun dalam penelitian ini dipilih tiga bangunan yang dikembangkan sebagai cagar budaya, yaitu Benteng Rotterdam, Museum Kota dan Gedung Kesenian Makassar. Ketiga bangunan bersejarah dipilih sebagai lokasi penelitian karena potensi fisik bangunan arsitektur yang dilengkapi dengan potensi bebas fisik nilai sejarah dan budaya. Penelitian yang diterapkan manajemen objek wisata ini, siklus hidup kawasan pariwisata oleh pelayan pribadi dan pemasaran pariwisata teori untuk mengetahui siklus hidup evolusi setiap bangunan kemudian mengatur strategi yang efektif untuk mengembangkan Fort Rotterdam, Museum Kota dan Gedung Kesenian sebagai cagar budaya di kota Makassar. Artikel berpendapat bahwa pemanfaatan Fort Rotterdam sebagai daya tarik turis diklasifikasikan ke dalam tahap pengembangan. Fort Rotterdam telah beberapa kali direnovasi dengan mengembangkan La Galigo Museum untuk meningkatkan daya tarik. Pemerintah daerah juga memiliki banyak promosi. Museum Kota dan Gedung Kesenian Makassar diklasifikasikan ke dalam tahap eksplorasi sejak dua bangunan bersejarah perlu perbaikan fisik, penataan ruang pamer dan fasilitas menangani koleksi Museum Kota dan jaminan bangunan pengelolaan dan pemeliharaan Gedung Kesenian. Berdasarkan hasil penelitian Fort Rotterdam, Museum Kota dan Gedung Kesenian Makassar tidak hanya memiliki potensi fisik bangunan dan nilai sejarah tetapi juga untuk menjadi daya tarik wisata yang menarik yang perlu ditingkatkan dengan mempertahankan identitas arsitektur sebanyak mungkin, memberikan fasilitas pendukung yang diperlukan oleh wisatawan dan meningkatkan promosi oleh pemerintah daerah.

4. Penelitian yang dilakukan Goenawan, dkk (2013) ${ }^{[14]}$ "Perancangan Video Promosi Pulau Bawean Beserta Media Pendukungnya". Kurangnya perhatian pemerintah terhadap pulau - pulau terpencil di pelosok Indonesia, menyebabkan tidak banyak masyarakat yang tau akan keberadaan serta potensi yang dimiliki dari tiap - tiap pulau tersebut. Pulau Bawean yang merupakan salah satu pulau terpencil yang berada ditengah perairan laut jawa, adalah pulau yang memiliki banyak sekali potensi dibidang pariwisata. Keindahan alam yang eksotis, masih alami dan belum banyak dijamah orang, sehingga dibuatlah media yang mempromosikan pulau ini dalam bentuk video promosi, masyarakat menjadi tau akan keberadaan serta potensi dari pulau ini, sehingga dapat berimbas pula terhadap jumlah wisatawan yang akan berkunjung ke pulau yang sedang berkembang ini.

5. Penelitian yang dilakukan Imam, dkk (2017) ${ }^{[21]}$ "Perancangan Media Promosi Video Youtube Koleksi Sanggar Gubug Wayang Mojokerto Berbasis Budaya Sebagai Upaya Meningkatkan Brand Awareness". Tujuan dari desain media promosi Sanggar Gubug 
Wayang Mojokerto di video youtube berbasis budaya adalah untuk meningkatkan kesadaran merek sebagai sumber informasi agar publik dapat mengetahui dan melestarikan budaya Indonesia. Penelitian ini menggunakan analisis penelitian dengan deskriptif kualitatif yang terdiri dari observasi, wawancara, dan sastra studi untuk mendapatkan data yang digunakan untuk mendukung produksi desain media promosi Sanggar Gubug Wayang Mojokerto di video youtube. Dan dianalisa menggunakan beberapa tahapan, yaitu pengamatan memperpanjang, meningkatkan kegigihan, triangulasi, negatif analisiskasus, penggunaan bahan referensi, dan menggunakan check.

\section{KESIMPULAN}

Media yang dibutuhkan Disporabudpar Kabupaten Tangerang dalam menginformasikan dan mempromosikan Pariwisata dan budaya Kabupaten Tangerang yaitu berupa media video informasi, karena menyajikan video yang informatif dan efektif mengenai keindahan Kabupaten Tangerang yang memiliki sejarah panjang dan menyimpan beragam potensi Pariwisata dan budaya Kabupaten Tangerang disertai voice over dengan penyampaian bahasa yang jelas, lugas, dan menarik. Selain itu tampilan visual yang selaras dengan audio dan efek visual yang disajikan, sehingga pesan yang disampaikan mudah dipahami oleh wisatawan.

\section{DAFTAR PUSTAKA}

[1] Alfira, Rizky. 2014. Identifikasi Potensi Dan Strategi Pengembangan Ekowisata Mangrove Pada Kawasan Suaka Margasatwa Mampie Di Kecamatan Wonomulyo Kabupaten Polewali Mandar. Makassar : Universitas Hasanuddin.

[2] Azizi, Nurul Zahirah Mohd. Arman Abdul Razak, Mokhtar Azizi Mohd Din, Nasyairi Mat Nasir. 2016. Recurring Issues in Historic Building Conservation. Procedia Social and Behavioral Sciences. Belanda : Elsevier B.V.

[3] Budiman, Ahmad. 2015. Model Pengelolaan Digitalisasi Penyiaran Di Indonesia. Jurnal Politica Vol. 6 No. 2. Jakarta : Pusat Pengkajian, Pengolahan Data dan Informasi (P3DI) Sekretariat Jenderal DPR RI.

[4] Christy, Priscilla. 2015. Pengaruh Desain Kemasan (Packaging) Pada Impulsive Buying. Yogyakarta : Universitas Atma Jaya Yogyakarta.

[5] Daniel. 2015. Pembuatan Video Profil Perguruan Swasta Buddhis Bodhicitta Medan. Medan : STMIK TIME.

[6] Desrianti, Dewi Immaniar. Sudaryono dan Dwi Ayu Ningrum. 2014. Enriching Media Merchandise Sarana Penunjang Promosi Studi Kasus Pada Bookstore. Journal CCIT Vol. 7, No. 3 ISSN: 1978 - 8282. Tangerang : Perguruan Tinggi Raharja.

[7] Dewi, Irna Kartina. 2015. Strategi Promosi Dalam Upaya Meningkatkan Produk Tabungan Tandamata My First Pada Bank BJB Kantor Cabang Pembantu Rancaekek. Bandung : Sekolah Tinggi Ilmu Ekonomi (STIE) EKUITAS.

[8] Effendy, Heru. 2014. Mari Membuat Film. Jakarta : PT Gramedia. 
[9] Faradiba, Lupita. 2015. Perlindungan Konsumen Melalui Gambar Peringatan Dalam Iklan Rokok Ditinjau Dari Undang-Undang No 32 Tahun 2002 Tentang Penyiaran Dan Undang-Undang No 8 Tahun 1999 Tentang Perlindungan Konsumen. Jawa Timur : Universitas Jember.

[10] Goenawan, Johan Christian. Arief Agung Suwasono. Daniel Kurniawan Salamoon. 2013. Perancangan Video Promosi Pulau Bawean Beserta Media Pendukungnya. Jurnal DKV Adiwarna Vol.1, No.2. Surabaya : Universitas Kristen Petra. 